\title{
Addition Protocols and Their Effects on Extraction and Retention of Grape Phenolics during Red Wine Fermentation and Aging
}

\author{
Glenn Jeffries
}

Oak Solutions Group, Napa, California 94558, United States

\begin{abstract}
Extraction and retention of red wine phenolics, particularly anthocyanins and tannin, have historically been a primary concern for many red wine producers. This research compares two competing protocols designed to facilitate the extraction and retention of grape phenolics through the addition of exogenous enological tannin to evaluate their relative effectiveness. The first protocol involves adding exogenous tannin in a single full-dose at or immediately after destemming/crushing the grapes. The second protocol, commonly referred to as the "sacrificial” protocol, involves splitting the addition into two half-doses. The first half-dose, or sacrificial dose, is applied at or immediately after destemming/crushing, and the second half-dose is added a few days later. The specific mechanisms involved in the extraction dynamics are not elucidated here, however, phenolic profiling before and during fermentation as well as one full year after, using UV-Vis and AWRI tannin portal methodology, has shown a clear advantage to the use of a single-dose protocol with respect to the extraction and retention of grape phenolics. Possible explanations are proposed and discussed.
\end{abstract}

Key words: Winemaking, tannin, wine color, anthocyanin, tannin extraction, tannin-protein interaction.

\section{Introduction}

In red wine production, the development of stable wine color and desirable textural properties tied to higher market value is closely correlated to the optimized extraction and retention of grape phenolics, particularly anthocyanins and tannin [1, 2]. The interactions between tannin and anthocyanins result in polymeric pigments that are generally more stable than monomeric pigments, and contribute significantly to improvements in color stability and sensory characteristics [3]. The presence of excess grape proteins liberated during crush or during the early stages of maceration could provide a potential mechanism for the inhibition of wine phenolic retention through competitive protein-tannin binding or protein-tannin-anthocyanin complexation and

Corresponding author: Glenn Jeffries, bachelor of chemistry, laboratory research chemist and technical consultant, research fields: oak aromatics, tannin and polyphenol chemistry. subsequent precipitation [4].

A protocol recommended by at least one tannin provider to deal with potential interferences from grape-derived proteins in must emphasizes adding enological tannin "sacrificially" during or immediately after crushing to fine out must proteins. The initial sacrificial tannin is expected to react with must proteins, leaving the anthocyanins, which extract at a faster rate than the grape tannins, uncomplexed and in a less stable state. Therefore, a second addition of enological tannin is added approximately 48 hours later to promote protection of and complexation with free anthocyanins as well as with the native grape tannins as they extract and become available.

To determine if this "sacrificial tannin" methodology is optimally effective with regard to promoting color development and phenolic retention during alcoholic fermentation in red wine, an experimental trial was performed on Pinot Noir during the 2015 US harvest. Pinot Noir was selected due to 
historically low color density and phenolic retention, therefore the relative effects of the tannin treatments were expected to be more easily discernable than with other common wine grape cultivars. In some cases, tannins were added in a single dose immediately after crushing, and in some cases they were added in two separate additions to determine if there was any apparent benefit from attempting to remove or deactivate potentially interfering must proteins prior to complexation of anthocyanins with tannins.

\section{Materials and Methods}

\subsection{Tannin Treatments}

Five treatments and a control were prepared to compare the relative effectiveness of several different types of enological tannins on the market when used as part of a sacrificial tannin protocol versus when used as part of a streamlined protocol that involves adding exogenous tannin in a single dose.

trū/tan fi Single Dose: A total dose of $10 \mathrm{~g} / \mathrm{hL}$ administered immediately after crushing.

$\operatorname{tru} / \tan \mathrm{f}^{2}$ Single Dose: A total dose of $10 \mathrm{~g} / \mathrm{hL}$ administered immediately after crushing.

trū/tan fi Split Dose: A total dose of $10 \mathrm{~g} / \mathrm{hL}$ split into two separate additions: $5 \mathrm{~g} / \mathrm{hL}$ added immediately after crushing and $5 \mathrm{~g} / \mathrm{hL}$ added on day 3 of primary fermentation.

$\operatorname{tru} / \tan \mathrm{f}^{2}$ Split Dose: A total dose of $10 \mathrm{~g} / \mathrm{hL}$ split into two separate additions: $5 \mathrm{~g} / \mathrm{hL}$ added immediately after crushing and $5 \mathrm{~g} / \mathrm{hL}$ added on day 3 of primary fermentation.

Brand X Split Dose: A total dose of $30 \mathrm{~g} / \mathrm{hL}$ split into two separate additions: $15 \mathrm{~g} / \mathrm{hL}$ of a tannin blend derived from chestnut and quebracho recommended by the manufacturer for removing unwanted protein, added immediately after crushing, and $15 \mathrm{~g} / \mathrm{hL}$ of a tannin blend derived from ellagic and catechinic sources recommended by the manufacturer to stabilize color, added on day 3 of primary fermentation.

$*_{\operatorname{tru}} / \tan \mathrm{fi}$ is a blend of hydrolysable tannins, with ellagitannin derived from lightly toasted oak heartwood and gallotannin derived from oak gallnuts, with total tannin up to $90 \%$.

**trū/tan $\mathrm{f}^{2}$ is a blend of hydrolysable tannins, with ellagitannin derived from heavily toasted oak heartwood and gallotannin derived from oak gallnuts, with total tannin up to $80 \%$.

\subsection{Fermentation}

Primary alcoholic fermentation was performed in-house using a micro-scaled approach. Sonoma Valley Pinot Noir grapes (Dijon 115 clone) were obtained, and for each variable approximately $23.5 \mathrm{lbs}$. of grape was weighed into a 3.5 gallon bucket in triplicate. A baseline sample was taken from each fermentation vessel and sent for initial analysis of color and phenolic profiling to account for any initial differences between buckets in grape must quality. Tannin treatments were then added to each bucket (except the control), followed immediately by gentle mixing and inoculation with Lalvin RC 212 strain of S. cerevisiae yeast (Lallemand). Punch downs were performed twice daily throughout the 14-day primary fermentation, along with brix and temperature readings. A second set of samples was taken from each fermentation vessel on day 3 and analyzed for phenolic profile. The treatments that were to receive a second dose of tannin were then dosed and gently mixed. All variables were fermented to dryness, and pressed off at the end of 14 days. A final set of samples was taken from each fermentation vessel for analysis of color and phenolic profile. Each variable was then composited into a single 4-liter green glass jug, and inoculated with Viniflora Oenos malolactic bacteria (Gusmer Enterprises) for monitoring of long term color and phenolic development.

\subsection{Analysis}

Red wine Total Phenolics, Total Tannin and Total Pigment are useful markers for overall wine quality, and have been shown to be positively associated with higher market value. These parameters can be 
quantitatively measured to help provide a more objective understanding of a wine's character and potential [1, 2]. To contrast the effects on overall wine quality between several tannin products as well as two different tannin addition protocols, the wines in this study were analyzed for these three key parameters using the AWRI Tannin Portal. The methodology developed largely by the Australian Wine Research Institute relies entirely on various UV-Vis Spectrophotometric measurements that are correlated to direct analysis for each phenolic parameter [5-9].

\section{Results and Discussion}

In Fig. 1, the Total Phenolics for each variable are compared both 3 days and 365 days after crushing. The Total Phenolics data, are shown as a percent change from the baseline reading on day 1 before any treatments were applied, shows no benefit to adding split doses of tannin by day 3 , and shows a disadvantage after 1 year. Fig. 2a shows the Total Tannin in g/L Catechin Equivalents. Here, wine tannin content consists almost entirely of native proanthocyanidic tannin from the grapes. Added exogenous enological tannin does not significantly impact the measurement of Total Tannin [7].

By day 14 post-crush, the fi Split Dose variable was marginally better than the fi Single Dose, but this may simply demonstrate that there seems to be a threshold of sufficient Total Tannin required to induce the effect on native tannin extraction, and adding significantly more than the threshold amount does not increase the native tannin extraction rate. However, by day 365 the FI Single Dose variable had retained more of the Total Tannin extracted versus the FI Split Dose. In addition, it shows that adding no tannin at all leaves most of the native tannin unextracted or unretained.

Fig. 2b shows the extraction kinetics of grape tannins. This clearly demonstrates the most important principal involved in grape tannin extraction and retention during fermentation - the extraction rate of native grape tannin is directly influenced by the addition of exogenous enological tannin. Furthermore, results presented in this figure indicate that the effect enological tannins provide is most significant on extraction rate and overall tannin extraction during the first three days of maceration, even though the extraction of tannin continues out to at least 14 days after crush.

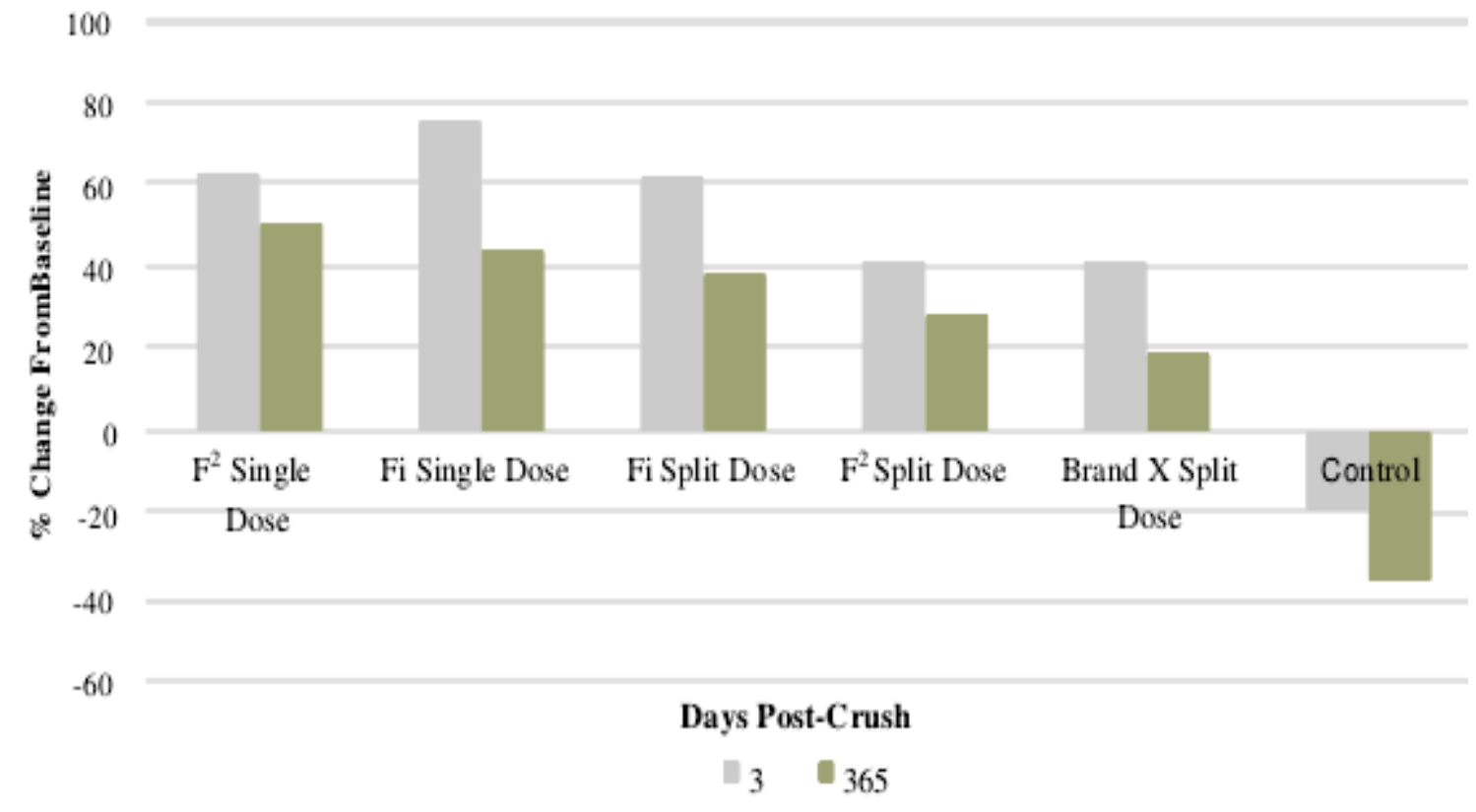

Fig. 1 Total phenolics. 


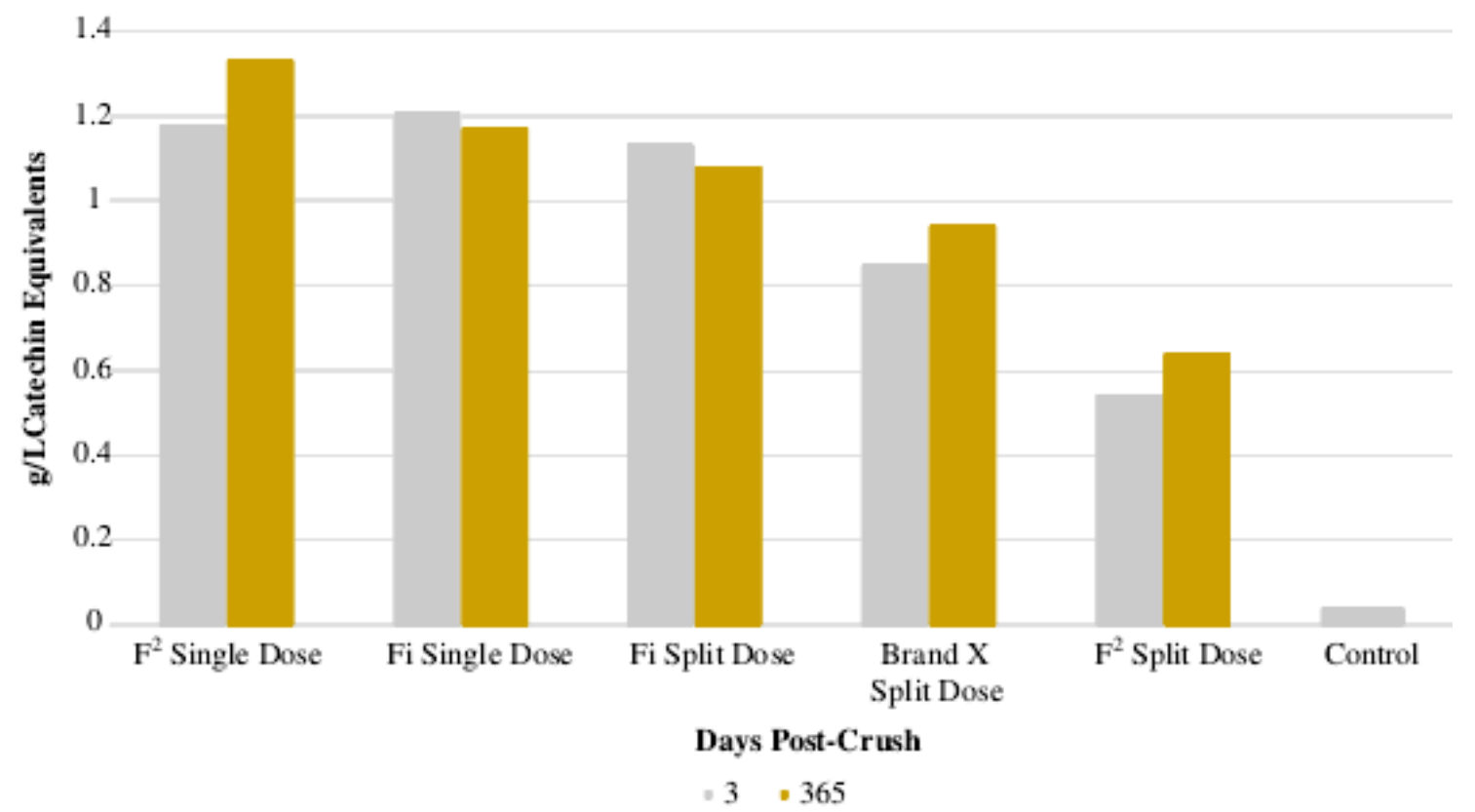

Fig. 2a Total tannin.

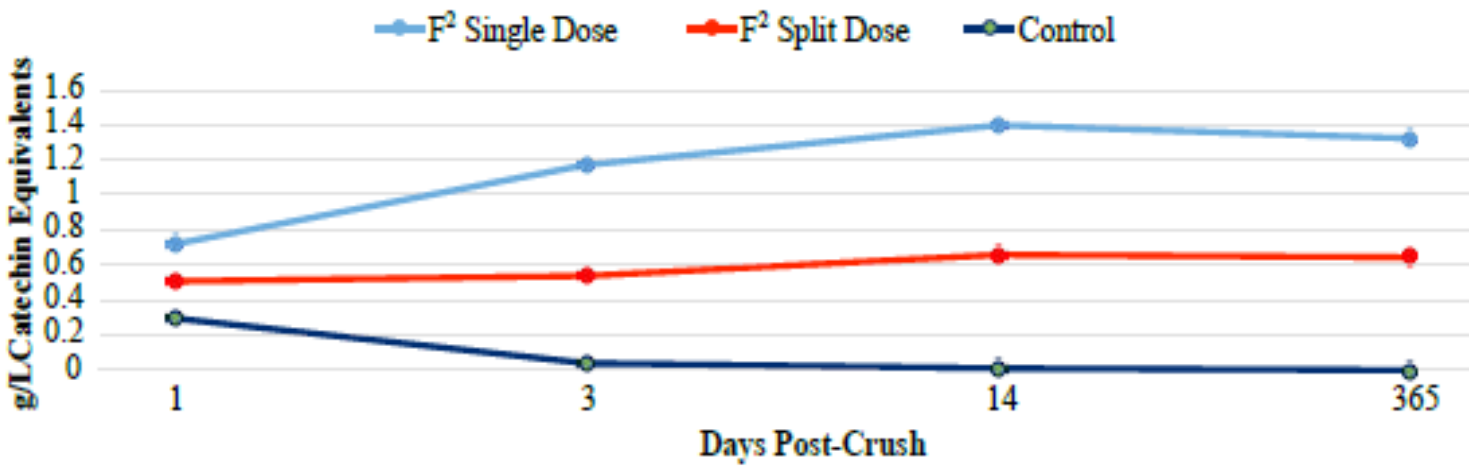

Fig. 2b Tannin extraction kinetics.

During this early stage of maceration, the Total Tannin for the $\mathrm{f}^{2}$ Single Dose variable increased sharply, while the $\mathrm{f}^{2}$ Split Dose remained relatively unchanged. The control experienced a significant loss of tannin during that period, which may be due to interactions between tannin already in the aqueous phase of the must and grape cell wall proteins [4].

After the addition of the second dose of tannin, which occurred on day 3, the extraction rates of the Split Dose and Single Dose variables were almost identical. This is quite possibly due to the grape cell wall proteins being further deactivated by the second dose of exogenous tannin, allowing for the free extraction of the grape tannin. However, the overall extraction for the Single Dose variable is still much greater, both in absolute terms as well as in terms of percent change from baseline. These differences are still apparent 365 days after crush, and indicate a lower tannin extraction and retention potential when a Split Dose exogenous tannin addition protocol is used.

Fig. 3a shows the absolute impact of each treatment variable on Total Pigment at 3 and 365 days post-crush. Total Pigment incorporates both the levels of Pigmented Tannin and Free Anthocyanins, and 
represents the best assessment of Total Anthocyanins and therefore overall color potential for a wine. There was no advantage shown at any point from adding tannin treatments in split doses, and by day 365 , the $\mathrm{f}^{2}$ and fi Single Dose variables showed better Total Pigment development than their Split Dose counterparts. All of the trū/tan variables showed more Total Pigment than either the Brand X Split Dose or the Control after 1 year.

It is well documented that anthocyanins extract much more rapidly from grapes than do tannins. However, the critical period for extraction for both types of compounds is during the first three days of maceration. More importantly, in Fig. 3b, the data clearly indicate that anthocyanin extraction is dramatically impacted by the addition of oenological tannin during early maceration. It also suggests anthocyanins may interact with grape proteins and polysaccharides in a way that is similar to the way grape tannins interact with grape proteins and polysaccharides.

The differences in effective day 1 exogenous tannin dose rate can be found in Fig. 4, and may help provide an explanation for the results found in this study. The

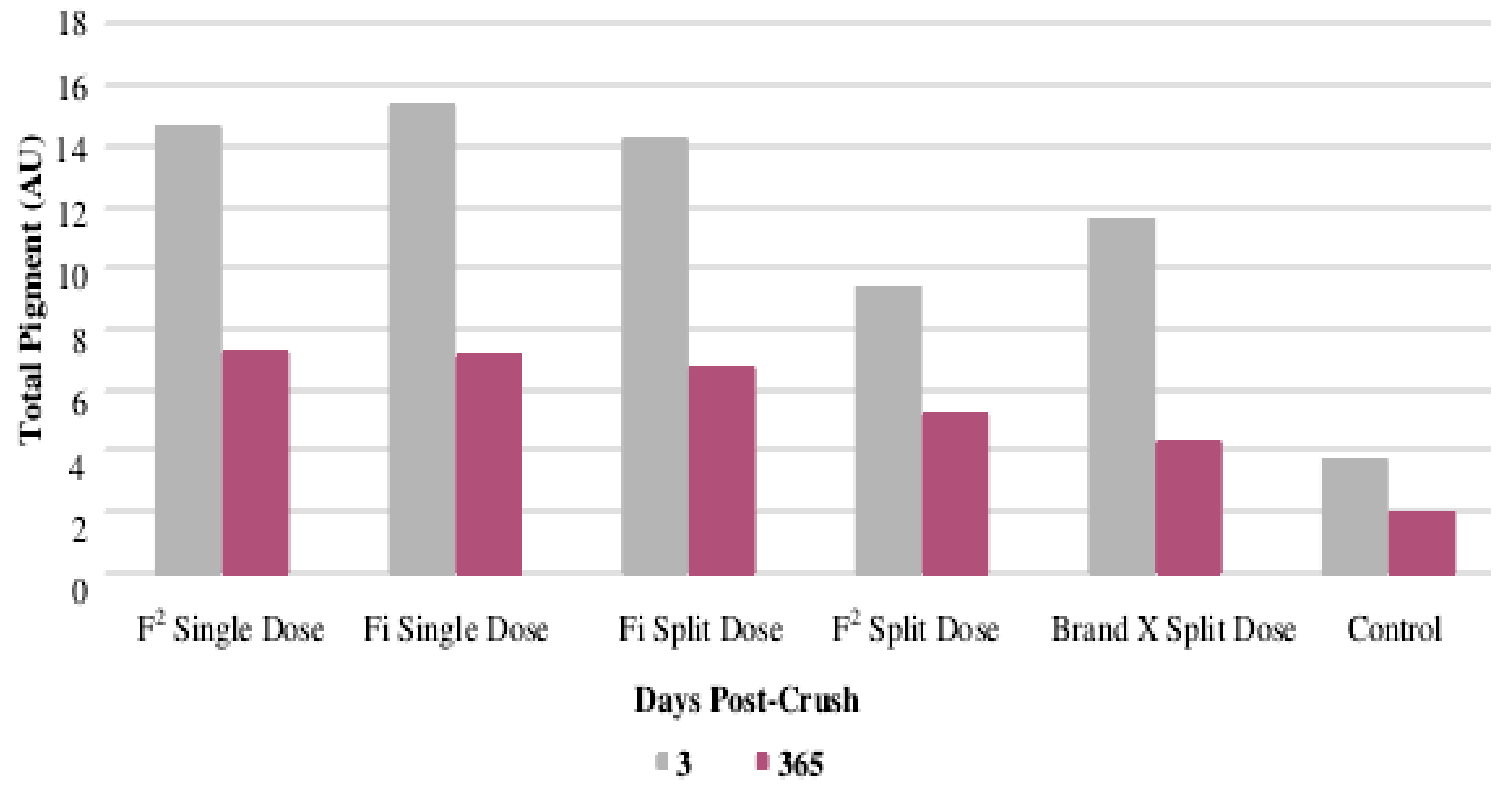

Fig. 3a Total pigment.

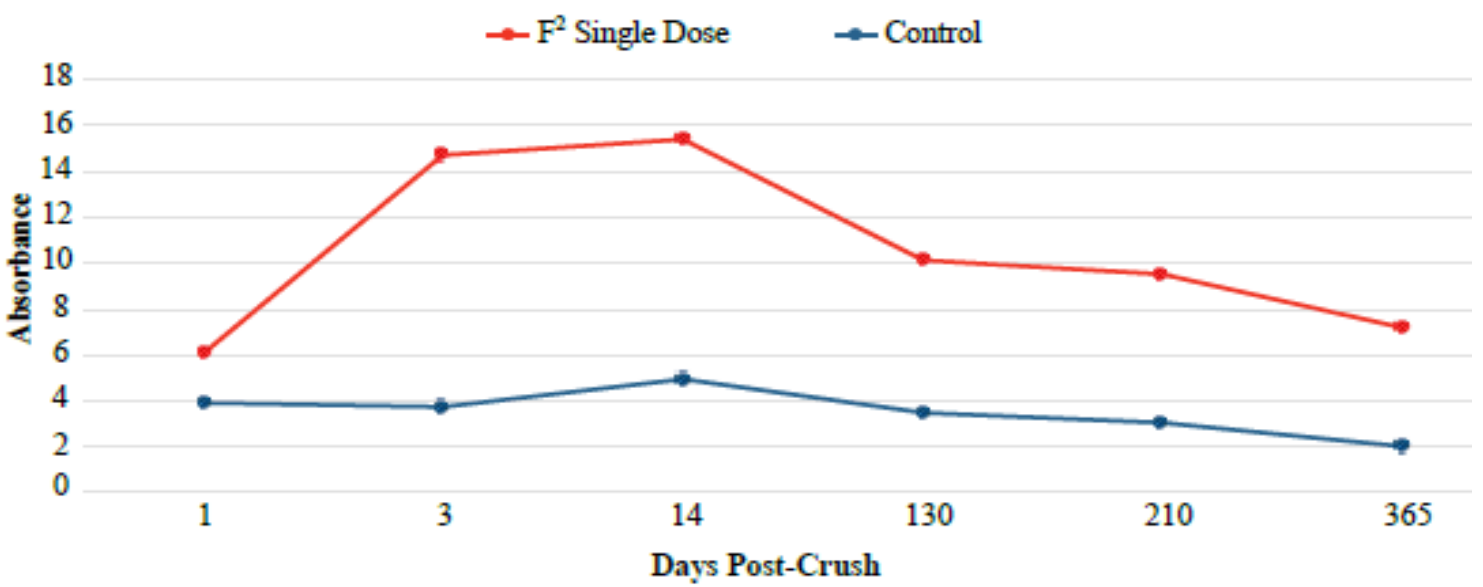

Fig. 3b Anthocyanin extraction kinetics. 
Grape Phenolics during Red Wine Fermentation and Aging

\begin{tabular}{llll}
\hline & $\begin{array}{l}\text { \% Total phenolics } \\
\text { (gallic acid equivalents) }\end{array}$ & $\begin{array}{l}\text { Day 1 exogenous tannin dose } \\
\text { rate }(\mathrm{g} / \mathrm{hL})\end{array}$ & $\begin{array}{l}\text { Effective day 1 exogenous } \\
\text { tannin dose rate }(\mathrm{g} / \mathrm{hL})\end{array}$ \\
fi Single & 91 & 10 & 9.1 \\
$\mathrm{f}^{2}$ Single & 77.2 & 10 & 7.72 \\
fi Split & 91 & 5 & 4.55 \\
$\mathrm{f}^{2}$ Split & 77.2 & 5 & 3.86 \\
Brand X Split & 22.2 & 15 & 3.33 \\
\hline
\end{tabular}

Fig. 4 Phenolic content of enological tannin products.

trend in the data shows generally that variables with higher effective day 1 exogenous tannin dose rates resulted in wines with greater Total Phenolics, Total Tannin and Total Pigment. This is to be expected if the exogenous tannin competes with native grape tannin for active sites available on the surface of pathenogenic related proteins or other potentially interfering grape-derived macromolecules.

\section{Conclusions}

This experiment has shown that a larger dose of exogenous tannin earlier during the maceration process provides a significant increase in the extraction and retention of key phenolic markers in red wine.

The initial Total Pigment data indicate that color is elevated versus a wine fermented with no treatment. This is due, in large part, to the well understood relationship between anthocyanins and tannin. Anthocyanins have a much higher stability when associated with tannin, and because they extract from grape skin and stems at a higher rate than tannin is extracted from grape skin and seed, the use of enological tannin helps to prevent anthocyanin loss during early maceration [4]. Additionally, adding exogenous tannin at a sufficiently high concentration during early maceration increases the rate of extraction of both tannins and anthocyanins from grapes. The presence of available tannin in the must may provide a mechanism for both native tannin and anthocyanins to overcome the interference that grape skin cell wall proteins and other compounds potentially represent to their extraction $[4,10]$.

The trū/tan products performed significantly better as a group with respect to the red wine market value predicting parameters Total Phenolics, Total Tannin and Total Pigment than did the Brand $X$ tannin, even at one-third of the dose rate. This phenomenon is expected, given the stark differences in Total Tannin content measured between the trutan products and Brand X. Direct interaction between hydrolysable tannin and anthocyanins may also help to explain the results, and future studies to elucidate those interactions are planned [11-13].

The data did not support the hypothesis that using exogenous enological tannin products as part of a sacrificial protocol provides any benefit at all. In fact, when there was a significant effect, it was a negative one. The $\operatorname{tru} / \tan \mathrm{f}^{2}$ Single Dose performed very well versus the $\mathrm{f}^{2}$ Split Dose, and the Brand $\mathrm{X}$ sacrificial protocol performed poorly in all of the categories measured. The fi Split Dose performed well, but that could be explained by the higher Total Tannin content of fi relative to the other enological tannin products that were part of this study.

As a practical methodology for winemakers during fermentation, using a single dose is far preferable to making multiple applications of tannin. Efficiency is increased as well as labor costs lowered. The lower dosage requirements that result from trū/tan products' higher total tannin content also conserve winery and warehouse space, and most importantly, lower the relative cost of product use to levels that are competitively advantageous.

Therefore, to most efficiently and effectively maximize the market value of red wine by dramatically improving native tannin and anthocyanin extraction and retention, while simultaneously 
streamlining enological tannin addition protocol, it is recommended to use a single dose of $\operatorname{tr} \overline{\mathrm{u}} / \tan \mathrm{f}^{2}$ or fi at a moderate level of $10 \mathrm{~g} / \mathrm{hL}$ during early primary fermentation.

\section{References}

[1] Mercurio, M. D., Dambergs, R. G., Cozzolino, D., Herderich, M. J., and Smith, P. A. 2010. "Relationship Between Red Wine Grades and Phenolics. 1. Tannin and Total Phenolics Concentrations.” J. Agric. Food Chem. 58 (23): 12313-9.

[2] Kassara, S., and Kennedy, J. A. 2011. "Relationship between Red Wine Gradeand Phenolics. 2. Tannin Composition and Size.” J. Agric. Food Chem. 59: 8409-12.

[3] Somers, T. C., and Evans, M. E. 1974. "Wine Quality: Correlations with Coulor Density and Anthocyanin Equilibriaina Group of Young Red Wines.” J. Sci. Food Agric. 25: 1369-79.

[4] Sparrow, A., Dambergs, R., Bindon, K., Smith, P., and Close, D. 2015. "Interactions of Grape Skin, Seed, and Pulpon Tanninand Anthocyanin Extraction in Pinot Noir Wines.” Am. J. Enol. Vitic 66: 4.

[5] Somers, T. C., and Evans, M. E. 1977. "Spectral Evaluation of Young Red Wines: Anthocyanin Equilibria, Total Phenolics, Freeand Molecular $\mathrm{SO}_{2}$, 'Chemical Age'.” J. Sci. Food Agric. 28: 287-9.

[6] Somers, T. C., and Evans, M. E. 1977. "Spectral Evaluation of Young Red Wines: Anthocyanin Equilibria, Total Phenolics, Free and Molecular $\mathrm{SO}_{2}$, 'Chemical Age'.” J. Sci. Food Agric. 28 (3): 279-87.
[7] Mercurio, M., Dambergs, R., Herderich, M., and Smith, P. 2007. "High Through Put Analysis of Red Wine and Grape Phenolics-Adaptation and Validation of Methyl Cellulose Precipitable Tannin Assay and Modified Somers Color Assay to a Rapid 96 Well Plate Format.” J. Agric. Food Chem. 55: 4651-7.

[8] Mercurio, M., and Smith, P. 2008. “Tannin Quantification in Red Grapes and Wine: Comparison of Polysaccharide and Protein-Based Tannin Precipitation Techniques and Their Ability to Model Wine Astringency.” J. Agric. Food Chem. 56: 5528-37.

[9] Harbertson, J. F., and Spayed, S. 2006. "From the ASEV 2005 Phenolics Symposium-Measuring Phenolics in the Winery.” Am. J. Enol. Vitic 57 (3): 3280-8.

[10] Lee, J. 2010. "Degradation Kinetics of Grape Skin and Seed Proanthocyanidinsina Model Wine System.” Food Chem. 123: 51-6.

[11] Saucier, C., Jourdes, M., Glories,Y., and Quideau, S. 2006. "Extraction, Detection, and Quantification of Flavano-Ellagitannins and Ethylvescalaginina Bordeaux Red Wine Agedin Oak Barrels.” J. Agric. Food Chem. 54: 7349-54.

[12] GarciaEstevez, I., Jacquet, R., Alcode-Eon, C., Rivas-Gonzalo, J. C., Escribano-Bailon, M. T., and Quideau, S. 2013. "Hemisynthesisand Structural and Chromatic Characterization of Delphinidin 3-O-Glucoside-Vescalagin Hybrid Pigments.” J. Agric. Food Chem. 61: 11560-8.

[13] Sousa, A., Mateus, N., Silva, A. M. S. S., Vivas, N., Nonier, M. F, Pianet, I., and de Freitas, V. 2010. "Isolation and Structural Characterization of Anthocyanin-Furfuryl Pigments.” J. Agric. Food Chem. 58: 566. 